\title{
Influence of Differences Baits on the Result of Laher Fishing (pentapodus trivittatus)
}

\author{
Julius Mose Rahaningmas* \\ Department of Technology of Fishery Products Prodi Management of Capture Fishery Engineering, PoltekTual, \\ Maluku, Indonesia
}

*Corresponding Author: Julius MoseRahaningmas, Department of Technology of Fishery Products Prodi Management of Capture Fishery Engineering, PoltekTual, Maluku, Indonesia

\begin{abstract}
This study used anchovy bait (sardinella leiogaster) and tumel bait (dendronereispinnaticirris) for fishingLaher fish (pentapodus trivittatus) on the Fair island, Tual city, Maluku province. The goal is to determine which baits most collect the Laher fish the and determine the most effective time to catchingLaher fish. The method used is a complete randomized ANOVA (RAL) statistical analysis to see the ratio of feeds to the number of Laher fish catches and comparative descriptive analysis to see catches based on catching time.The research which lasted for 30 days obtained a total number of Laher fish are 512 fish. The ANOVA statistical test results of a completely randomized design at the 95\% confidence level $(\alpha=0.05)$ are Fhit $=$ 77.38>Ftab $=4.01$. This shows that HO is rejected and H1 is accepted. The conclusion is that the number of Lahers taken by anchovy bait and tumelbait is not the same, that is, the tumelbait can be catchingLaher319 fish $(62 \%)$ while the anchovy feed only gets 193 or 38\%.Furthermore, the time of Laher fishing in the morning from 06:00 to 09:00 CEST produces 354 tails (69\%) while in the afternoon at 3:00 a.m. to 6:00 p.m. WIT only gets 158 fish or $31 \%$.
\end{abstract}

Keywords: anchovy, tumel, laher, fair island, Tual city

\section{INTRODUCTION}

The Kei Islands consist of the city of Tual and Southeast Maluku Regency. Both of these regions have considerable fisheries potential on the coast and in the sea. Types of reef fish and demersal fish always choose the waters of the Kei islands as their place of life (Rahaningmas\&Renjaan 2018).

The fish Pentapodus trivittatus (family of nemipteridae) includes demersal fish that live in coastal ecosystems near coral reefs and seagrasses. According to Phinrub et al (2014) explained that Laher fish are found regularly in seagrass beds whose water depths range from 5-30 m.

Laher fish resources are spread in almost all Indonesian waters. One of them is in the waters of Fair Island, Tual City, Maluku province, which has sandy and rocky waters and has a seagrass ecosystem which is a habitat for several demersal fish including Laher fish (Kusnadi 2008).

The distinctive feature of the Laher fish body is the dark gray or olive brown upper part and silvery white lower body. The flesh is reddish white and contains high nutritional value so the Laher fish has an economic value (Pamuji et al 2018). The fishing community in the city of Tual and Southeast Maluku, Maluku province knows pentapodus trivittatus fish with the name fish Laher.

Research activities use line fishingto catch Laher fish. The main advantage of stretching fishing rods is that the quality of the catch is always good and another advantage is that stretching construction is very simple and the material is cheap and can be operated at various depths of water (Rahaningmas et al 2014).

The success of catching Laher fish using stretch fishing rods is largely determined by bait. Siswoko et al 2013) explained that fishing would be more effective if the bait used could invite or stimulate fish. The same opinion was also reinforced by Rahaningmas\& Mansur (2018) which states that the bait function is a lure to attract attention so that fish come close to the fishing line to prey on bait.

The type of bait that is always used by fishermen to catch Laher fish (pentapodus trivittatus) is anchovies (sardinella leiogaster) and lur worms or tumel (dendronereispinnaticirris). This shows that fishermen have not been able to prove which bait is the most effective of the two types of bait. 
The purpose of this study was to determine which bait caught the most Laher fish (pentapodus trivittatus) and determine the most effective time to catch Laher fish (pentapodus trivittatus).

\section{Materials And Methods}

The method used in this study was to conduct a trial directly at the Laher fish pond. The activity took place in September 2019 in the waters of Fair Island, Tual city, Maluku province. The location of the study can be seen in Figure 1

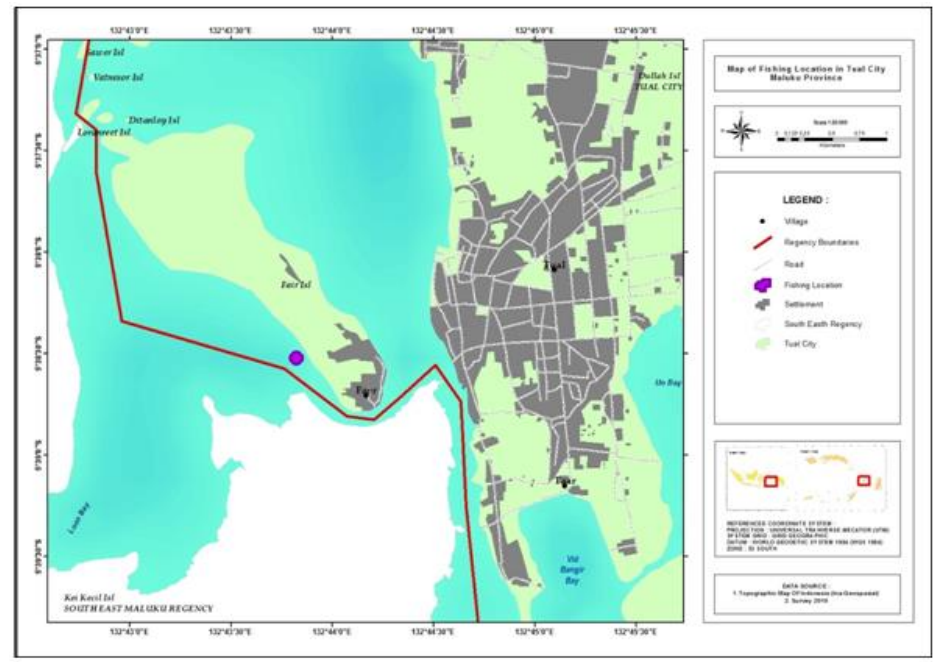

Figure1. Research location

\subsection{Materials and Tools}

The research material used was anchovies bait (sardinella leiogaster) and tumel bait (dendronereispinnaticirris). Figure 2 shows both types of bait and line fishing constructions. The research equipment consisted of one fishing boat unit, plastic rollers $\varnothing 20 \mathrm{~cm}$, polyamide rope (PA) monofilament number 500, kili-kili and fishing line number 18 .

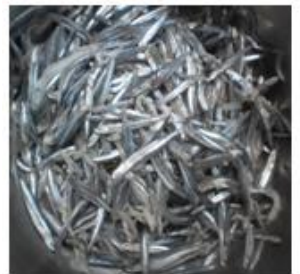

(1)

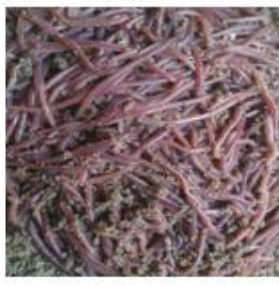

(2)

Information:

(1) Anchovy bait(sardinella leiogaster):

(2) Tumel bait(dendronereispinnaticirris);

(3) Plastic roller;

(4) Fishing line:

(5) Kili-kili;

(6) The main rope;

(7) Branch rope; and

(8) Fishhook.

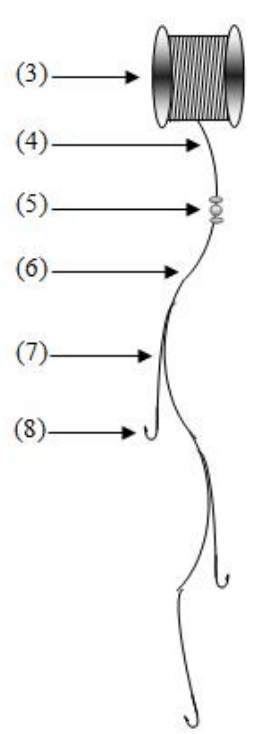

Figure2. Type of bait and stretching construction

\subsection{Research Methods}

The method used in this study is the experimental method by conducting trials directly in the field. Laher fishing operations using stretch fishing rods, each of which has been installed anchovy bait and tumel bait.

Laher's fishing activities are divided into two times, namely in the morning at $06.00-09.00$ WIT and in the afternoon at 15. 00-18. 00 WIT. The distance between the catchment area and the coast is \pm 1 mile and the water depth is around $10 \mathrm{~m}$. Two anglers who are both in one boat operate stretching 
rods, each of which is composed of three fishing rods. Each angler uses anchovy bait and tumel bait. Figure 3 shows the sequence of Laher fishing operations.

\section{Seqiuence of Laher Fishing Operations}

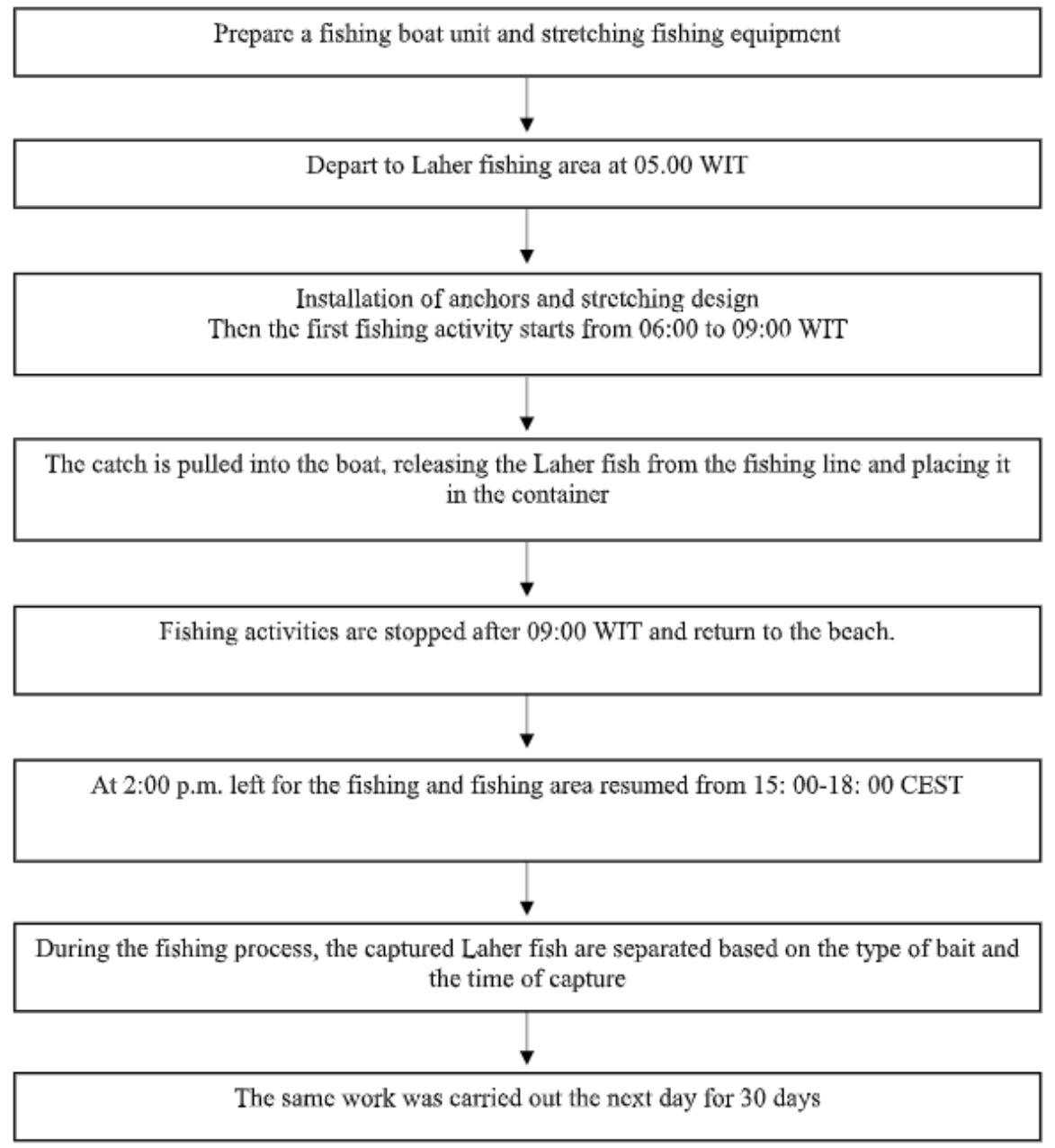

Figure3. Laher fishing squence (pentapodus trivittatus)

\subsection{Data Analysis}

There are two types of data analysis used in this study, namely descriptive analysis to see the differences in fishing time of catches, and ANOVA statistical analysis of completely randomized design (CRD) to see the effect of the type of bait on the number of catches.

$Y i j k=\mu+\tau i+\delta i j+\varepsilon i j k ; i=1,2,3, \ldots$ etc.; and $j=1,2,3 \ldots$ etc.

Yijk is observing the treatment of $-\mathrm{i}$, the repetition $-\mathrm{j}$ and the sub example $-\mathrm{k} ; \mu$ middle population; : $\tau \mathrm{i}$ : treatment ofi; $\delta \mathrm{ij}$ : the effect of the repetition $-\mathrm{j}$, the treatment of -i; and cijk: sub example error. The assumptions needed for this analysis are 1) additive, homogeneous, free, and normal; 2) $\tau \mathrm{i}$ is permanent; and 3) $\varepsilon i j \mathrm{k} \sim \mathrm{N}(0, \delta 2)$.

The hypotheses tested are:

Ho: $\tau 1=\tau 2=\tau 3=\ldots \ldots=\tau 5=0$; and

Ho: $\tau 1=\tau 2=\tau 3=\ldots \ldots .=\tau 5 \neq 0$

The conclusion is :

if Fhit>Ftab, then Ho is rejected and $\mathrm{H} 1$ is accepted,

then if Fhit $<$ Ftab, then Ho is accepted and $\mathrm{H} 1$ is rejected. 


\section{RESULTS AND DISCUSSION}

\subsection{Morphology of Laher Fish}

The location of the Laher fish head (pentapodus trivittatus) is closer to the eye. There are a few scales under the eyes. The upper body color is gray with a narrow pale saddle pattern on its back, there are pale lines that follow the lateral line, the white mid lateral line is often wide and forms a white pattern, wide gray lines on the muzzle, a pair of blue lines behind the eyes and a gray from the low back corner of his eye to the lower part of the operculum. Morphology of Laher fish caught during the study can be seen in Figure 4.

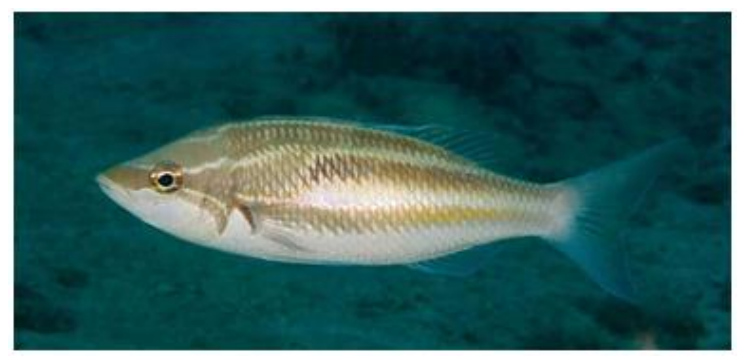

Figure4. Laher fish (pentapodus trivittatus)

The total amount of fish caught which lasted for 30 days was 512 fish. Laher fish catch per day is very diverse and can be seen in Figure 5.

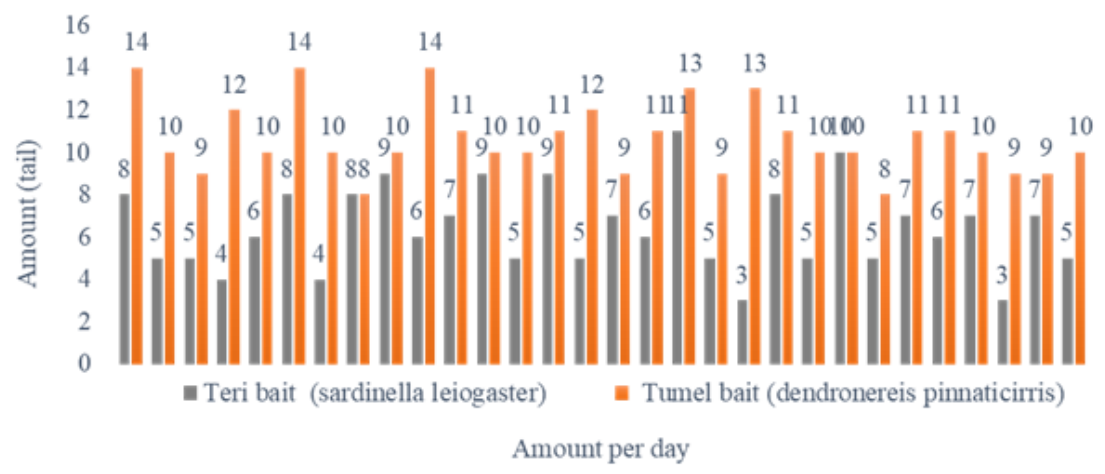

Figure5. Amount of catch of fish Laher (Pentapodus trivittatus) per day

Anchovy and tumel baits used to catch Laher fish during the research and always get a response from Laher fish. The type of tumel bait that more catches Laher fish is between 8 to 14 per day. While anchovy bait only gets 3 to 11 per day.

The results showed that every day there were always Laher fish caught using anchovy and tumel bait. The results of the study of Syukur et al (2017) which explain that Laher fish are eaters of small fish (anchovy bait) and worms (bait tumel).

\subsection{Catches Based on Types of Bait}

Laher fish responds to anchovy and tumel bait so that the total number of Laher fish catches is very large, which is 512. Figure 6 shows the number of Laher fish caught during the study.

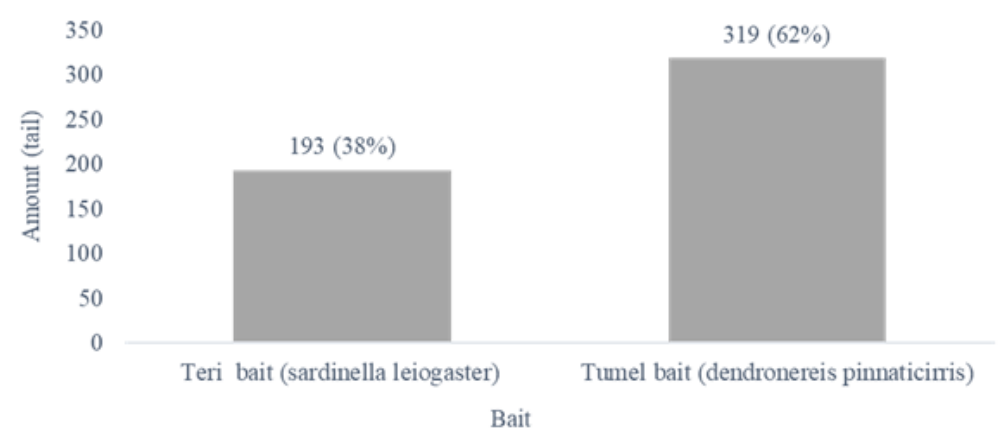

Figure6. Catch of Laher fish (pentapodus trivittatus) based on the type of bait 
Based on Figure 6, it shows that the tumel bait which catches laher fish is more than 319 fish or 62\%, while anchovybait only gets 193 fish or $38 \%$.

The ANOVA statistical test results of a completely randomized design at the confidence level $95 \%$ ( $\alpha$ $=0.05)$ are $\mathrm{F}_{\text {hit }}=77.38>\mathrm{F}_{\text {tab }}=4.01$. This indicates that $\mathrm{H}_{0}$ is rejected and $\mathrm{H} 1$ is accepted. So the conclusion is the number of Lahers (pentapodus trivittatus) caught by anchovy bait and tumel bait are not the same or are significantly different.

Laher fish eat more tumel bait than anchovy bait because Laher fish and tumel always look for food in the same habitat. According to Hermawan et al (2015) explain that dendronereispinnaticirris or tumel can live on soft sand substrates. Phinrub et al (2015) stated that Laher fish is found in sandy areas. Furthermore, Syukur (2016) explains that most seagrass watersheds have sandy substrates.

In addition, Laher fish prefers to eat tumel bait because of its unique characteristics, it has been known by Laher fish as its predators. According to Onthoni (2017), explaining that the smell of bait that is sharp and long-lasting in water can stimulate fish to come near and eat it because generally reef and demersal fish rely more on their sense of smell to forage.

\subsection{Fishing Time-Based Catches}

Laher fishing activities are divided into two periods, namely the first period takes place from 06:00 09:00 WIT and the second period is from 15:00 to 18:00 WIT. Laher catches in the morning and afternoon can be seen in Figure 7.

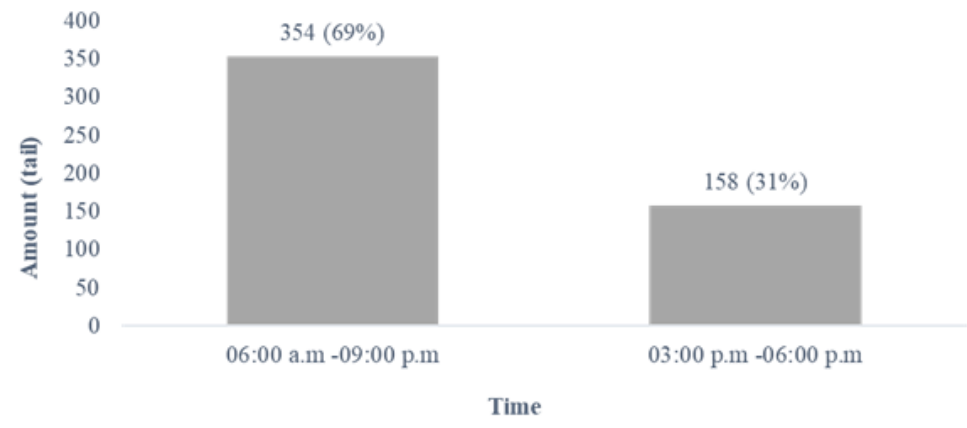

Figure7. Results of catch of fish Laher (pentapodus trivittatus) based on fishing time

The largest catch of Laher fish is at intervals between 06:00 and 09:00 WIT, totaling 354 fish or 69\%, while the interval between 15:00 and 18:00 WIB only gets 158 fish or 31\%.

Laher fishing activities are carried out in two different time periods. The first period, which is 6:00 a.m. to 9:00 p.m., gets 354 tails $(69 \%)$ of the total catch of 512 tails. While the second period was carried out in the afternoon at 3:00 p.m. until 6:00 p.m. WIT received 158 tails or 31\% of the total number of Laher fish catches.

The number of Laher fish catches in the first period was more than the second period. This happens because Laher fish is a type of diurnal fish (active during the day) that rests at night and just comes out of a hiding place to look for food in the morning. According to Latuconsina et al (2014), it is explained that the nemipteridae family always rests and hides between corals at night and because of its diurnal nature so that this family is always active during the day.

In addition, the condition of the waters that are quite calm can make it easier for fish to detect the presence of bait so that the activity of feeding time can be carried out properly and smoothly. Furthermore, the fish caught are fish that are crossing the fishing ground or coinciding with the time of fish activity foraging for food.

The period of Laher fishing at 15: 00-18: 00 WIT or the second period only gets 158 fish (31\%). This shows that the catch of the second period is less than the first period. The reason is because the condition of bright waters can allow fish to start looking for other types of food. According to Pamuji et al (2018) explain that fish will change food according to the needs, abilities and availability of food in the waters.

In addition, fish caught are fish that are passing through the fishing grounds to go to hiding places or fish that will return to hiding places. This is in accordance with the opinion of Latuconsina et al 
(2014) which explains that the abundance of Nemipteridae fish is variety throughout the day, where migration activities occur mostly in the morning to find food and in the afternoon go to hiding places.

\section{CONCLuSion}

The results of research conducted for 30 days received a total of 512 fish.

The conclusion is:

- The type of bait that most catches Laher fish (pentapodus trivittatus) is the bait tumel (dendronereispinnaticirris) totaling 319 fish (62\%), while anchovy bait (sardinella leiogaster) only gets 193 fish or $38 \%$.

- The most effective time for Pentapodus trivittatus fishing is in the morning from 06:00 to 09:00 WIT as much as 354 fish (69\%) and during the day, 15: 00-18: 00 WIT only get 158 fish or $31 \%$.

\section{REFERENCES}

[1] Anonymous., 2015. Fish Laher (pentapodus trivittatus) [internet]. [downloaded Februari 09, 2020] Available at: http://www.fishbase.se/Summary/SpeciesSummary.php?id=5873\&lang=bahasa

[2] Hermawan D., Saifullah., Herdiyana D., 2015 The Effect of Different Substrates of Culture (nereissp). Journal of Fisheries and Marine 5 (1): 41-47

[3] Kusnadi A., Triandiza T., Hernawan U. E., 2008 The inventory of mollusc species and its potent on seagrass beds in Kei Kecil Islands, Southeast Moluccas. Biodiversity 9 (1): 30-34

[4] Latuconsina H., Sangadji M., Sarfan L., 2014 Structure of Seagrass Fish Community in Wael Bay Kotania Beach, West Seram Regency. Agribusiness Scientific Journal and Fisheries 6 (3): 24-32

[5] Onthoni J. G., Manoppo L., Pamikiran R. D. C., 2017 The Marore Islands District, Marore Islands District. Journal of Fisheries Science and Technology Capture 2 (6): 217-222

[6] Pamuji., Yadisi F., Haslianti., 2018 Food habits of Three-Striped Whiptail (Pentapodus trivittatus) in Bungingkela waters Bungku District Morowali Regency. Journal of Management of Aquatic Resources 3 (1): 11-19

[7] Phinrub W., Montien-Art B., Promya J., Suvarnaraksha A., 2014 Fish diversity and fish community at Ban Pak Klong, Trang Province, Thailand. International Journal of Fisheries and Aquatic Studies 2 (2): 197201

[8] Phinrub W., Montien-Art B., Promya J., Suvarnaraksha A., 2015 Fish Diversity and Fish Assemblage Structure in Seagrass Meadows at Sikao Bay, Trang Province, Thailand. Journal of Ecology 5 (2): 563-573

[9] Rahaningmas J. M., Puspito G., Diniah., Wahju R. I., 2014 Hairtails Fishing (trichiurus sp.) Effectiveness Using Artificial Bait. Journal of Fisheries and Marine Technology 5 (1): 33-40

[10] Rahaningmas J. M., Mansyur S., 2018 The Influence of Differences in the Types of Cockatoo Fish (Family: Scaridae) Caught Using Handlines. Indopasific Aquatic Resources Journal 2 (1): 25-34

[11] Rahaningmas J. M., Renjaan M. R., 2018 The Influence of the Bait of Fishing of Sakuda (LethrinidaeFamily) Using Fishing Line. International Journal of Innovative Studies in Aquatic Biology and Fisheries, 4 (1): 3-19

[12] Siswoko P., Pramonowibowo., Aristi D. P. F., 2013 The Fish Catching Use Fishing Rod Coping (hand line) in the Fishing Ground Waters of Pacitan, East Java. Journal of Fisheries Resources Utilization Management and Technology 2 (1): 66-75

[13] Syukur A., 2016 Seagrass Conservation for the Sustainability of Fish Resources in Indonesian Coastal Waters. Journal of Tropical Biology 16 (1): 56-68

[14] Syukur A., Wardiatno Y., Muchsin I., Kamal M. M., 2017 Threats to Seagrass Ecology and Indicators of the Importance of Seagrass Ecological Services in the Coastal Waters of East Lombok, Indonesia. American Journal of Environmental Sciences 13 (3): 251-265

Citation: Julius Mose Rahaningmas, "Influence of Differences Baits on the Result of Laher Fishing (pentapodus trivittatus)", International Journal of Innovative Studies in Aquatic Biology and Fisheries, 6(2), pp. 5-10. DOI: http://dx.doi.org/10.20431/2454-7670.0602002

Copyright: () 2020 Authors, This is an open-access article distributed under the terms of the Creative Commons Attribution License, which permits unrestricted use, distribution, and reproduction in any medium, provided the original author and source are credited. 